\title{
Physical Properties of Organic Fullerene Cocrystals
}

\author{
Roberto Macovez* \\ Grup de Caracterització de Materials, Barcelona Research Center in Multiscale Science and Engineering, Department of \\ Physics, Universitat Politécnica de Catalunya, Barcelona, Spain
}

The basic facts and fundamental properties of binary fullerene cocrystals are reviewed, focusing especially on solvates and salts of Buckminsterfullerene $\left(\mathrm{C}_{60}\right)$, and hydrates of hydrophilic $\mathrm{C}_{60}$ derivatives. The examined properties include the lattice structure and the presence of orientational disorder and/or rotational dynamics (of both fullerenes and cocrystallizing moieties), thermodynamic properties such as decomposition enthalpies, and charge transport properties. Both thermodynamic properties and molecular orientational disorder shed light on the extent of intermolecular interactions in these binary solid-state systems. Comparison is carried out also with pristine fullerite and with the solid phases of functionalized $\mathrm{C}_{60}$. Interesting experimental findings on binary fullerene cocrystals include the simultaneous occurrence of rotations of both constituent molecular species, crystal morphologies reminiscent of quasicrystalline behavior, the

OPEN ACCESS

Edited by:

Diego Cazorla-Amoros, University of Alicante, Spain

Reviewed by: Andrea Goldoni, Elettra Sincrotrone Trieste, Italy Theodore A. Tsoufis, National Center for Scientific Research, France

*Correspondence: Roberto Macovez roberto.macovez@upc.edu

Specialty section: This article was submitted to Carbon-Based Materials, a section of the journal Frontiers in Materials

Received: 06 October 2017 Accepted: 11 December 2017 Published: 04 January 2018

Citation: Macovez R (2018) Physical Properties of Organic Fullerene Cocrystals.

Front. Mater. 4:46. doi: 10.3389/fmats.2017.00046 observation of proton conduction in hydrate solids of hydrophilic fullerene derivatives, and the production of super-hard carbon materials by application of high pressures on solvated fullerene crystals.

Keywords: buckminsterfullerene, functionalized $\mathrm{C}_{60}$, solvate, hydrate, crystal structure, rotational dynamics, thermodynamic properties

The unique features of the fullerene molecules enable a number of different routes for tuning their properties by molecular functionalization and formation of complexes. The hollow molecular structure of fullerenes allows, for example, endohedral complex formation, while their polyconjugated electronic structure enables multiple functionalization with covalently attached adducts (up to one adduct per carbon atom in the case of small groups, which for Buckminsterfullerene means up to 60 adducts) (Taylor and Walton, 1993). A third route for "tuning" fullerenes is cocrystal formation with other organic species in the solid state (Sundqvist, 2003; Neretin and Slovokhotov, 2004; Wang, 2015) or supramolecular complex-formation exploiting $\pi$ stacking interactions (Fernández et al., 2008; Babu et al., 2010). These three modification routes have been termed, in the case of salts of fullerenes with electron donor atoms or molecules such as alkali atoms or ferrocene, "endohedral," "on-ball," and "exohedral," respectively.

Here, I review the physical properties of some solid-state molecular compounds of pristine and functionalized Buckminsterfullerene $\left(\mathrm{C}_{60}\right)$, namely, cocrystals with small organic molecules including solvates and hydrates. Concerning the latter, while pristine $\mathrm{C}_{60}$ is not water soluble, functionalization with polar groups leads to derivatives with higher water affinity (Wang et al., 2005; Kokubo et al., 2008), which in some cases promotes the formation of hydrates from water solutions (Zachariah et al., 2015).

Fullerenes are quite peculiar molecules. No liquid fullerene phases are known, and binary phases with other molecules cannot be obtained by mixing and cooling from the molten state at arbitrary proportions. Intercalation of gas-phase molecules into solid fullerite can be achieved by application 
of pressure (and sometimes high temperature) to the molecular gas to aid its diffusion through the interstices of $\mathrm{C}_{60}$ crystals; this method only works, however, for rare gases, methane, or small diatomic gases (Sundqvist, 2003; Galtsov et al., 2007). On the other hand, fullerenes are moderately soluble in a number of organic solvents (Ruoff et al., 1993) and stoichiometric solvates can be obtained by precipitation or slow evaporation. $\mathrm{C}_{60}$ readily forms solvates with a large variety of solvents such as benzene, toluene, chlorobenzene, n-alkanes, halogenated ethane and methane derivatives, hexane, $\mathrm{m}$-xylene, and $\mathrm{CS}_{2}$. Many solvates are unstable at room temperature; the stable ones decompose upon heating either by incongruent melting or sublimation of the solvent alone. Cocrystals of fullerenes with non-solvent molecules can be obtained from co-solutions in a common (usually aromatic) solvent, either by slow concentration of the solution or by addition of a precipitant (bad solvent). These simple methods not only allow producing a variety of different binary compounds, but can be even employed to obtain quasi-pure fullerene crystals with tailored morphologies and a large variety of forms (Wang et al., 2006; Babu et al., 2010; Shrestha et al., 2013), in some cases with symmetries reminiscent of the quasicrystalline state (Fleming et al., 1991; Céolin et al., 1992; Michaud et al., 1998) and sometimes even with a modified lattice structure (de Boer et al., 1994; Céolin et al., 1999, 2001). In particular, $C_{60}$ crystals formed from solution may display hexagonal closed packed (hcp) lattice instead of the usual face-centered cubic (fcc) structure of pristine fullerite (Heiney et al., 1991) (the hcp and fcc structures only differ in the stacking alternation of close-packed triangular planes, but in the case of $\mathrm{C}_{60}$, this also entails a different orientational dynamics, see below).

The quasispherical shape of $\mathrm{C}_{60}$ results in crystals with relatively large interfullerene voids that can be occupied by small intercalants, even in the closed-packed ( $\mathrm{fcc}$ and hcp) structures of pristine fullerite. In compounds of $\mathrm{C}_{60}$ with $\mathrm{H}_{2}, \mathrm{NH}_{4}$, and $\mathrm{CO}$ which is obtained via gas-phase intercalation, for example, the room-temperature symmetry is fcc, with variations of the lattice parameter of less than $0.2 \%$ compared to pristine fullerite. Only a minor lattice distortion is observed in $\mathrm{N}_{2}$-intercalated $\mathrm{C}_{60}$, which is obtained at high pressure (Galtsov et al., 2007), while $\mathrm{O}_{2}$ can diffuse even at atmospheric pressure through the interstices of $\mathrm{C}_{60}$ (Assink et al., 1992), which rationalizes its observed degradability by photooxidation (Hamed et al., 1993; Katz et al., 1998). These intermolecular interstices, especially the larger octahedral ones, are large enough to accommodate also the heavier alkali ions without distortion nor expansion of the fcc lattice, and cocrystallization of alkali fullerides with ammonia leads to only minor tuning of the lattice spacing.

The fcc structure is also maintained in the 1:1 cocrystal with the cubane $\mathrm{C}_{8} \mathrm{H}_{8}$ molecule, thanks to the fact that the hydrogen groups at the vertices of the cubic carbon cage of the cubanes result in electronic orbitals with concave surfaces that are complementary to the convex spherical shape of the molecular electronic cloud of the buckyballs (Pekker et al., 2005). The idea of cocrystal formation exploiting the complementarity of the convex fullerene surface with molecules displaying saddle-like, concave surfaces (possibly with aromatic character), was introduced early on (Raston, 1996; Barbour et al., 1998; Hardie and Raston, 1999) and is one of the basic principles for the supramolecular organization of fullerenes, as reviewed in a recent book (Martin and Nierengarten, 2012).

While small, symmetric intercalants can preserve the closepacked structure of the fullerene species, resulting in crystal structures that are often cubic or hexagonal, most fullerene cocrystals display a more open and less symmetric structure (Neretin and Slovokhotov, 2004; Wang, 2015). This is the case of cocrystals with molecules of size comparable to that of the $\mathrm{C}_{60}$ molecule [whose van der Waals diameter is $\approx 10 \AA$ (Heiney et al., 1991)], but also with smaller aromatic molecules, and even with some tetragonal molecules such as $\mathrm{P}_{4}$ and $\mathrm{CCl}_{4}$. In many cases, both for high- and low-symmetry lattices, the crystal structure of fullerene cocrystals can be described as consisting of alternating layers of fullerenes and cocrystallizing species (Spitsina et al., 2002; Neretin and Slovokhotov, 2004; Cui et al., 2012; Mitsari et al., 2016a; Ye et al., 2017).

The interest in molecular fullerene cocrystals started soon after the discovery of a method for bulk production of $\mathrm{C}_{60}$ (Krätschmer et al., 1990) and was driven initially by the discovery of p-electron ferromagnetism in the molecular charge-transfer salt of $\mathrm{C}_{60}$ with tetrakys(dimethylamino)ethylene (Allemand et al., 1991) and further spurred by the quest to increase the critical temperature of fulleride superconductors by tuning their lattice spacing, which could be achieved by ammonia intercalation (Zhou et al., 1993). In some fullerides, lattice expansion via ammoniation leads instead to a metal-insulation transition and antiferromagnetism (Prassides et al., 1999). The appearance of magnetic properties and metal-insulator transitions is associated with the partial filling of the lowest unoccupied molecular orbital of $\mathrm{C}_{60}$, which is accompanied by Jahn-Teller distortions that lift the orbital degeneracy (threefold in fullerite).

Beside these electronic transitions, which are absent in pure $\mathrm{C}_{60}$, an interesting question is whether the orientational transitions of pristine fullerite survive in cocrystals with other organic molecules. At room temperature, fullerite exhibits an fcc rotator phase consisting of rapidly spinning molecules (the lattice symmetry is fcc because all free-rotor molecules are undistinguishable in a diffraction experiment). In hcp fullerite crystals, the molecules only display uniaxial (rather than free) rotation (Céolin et al., 1999). In fcc fullerite, below $260 \mathrm{~K}$ the dynamic orientational disorder is replaced by a ratcheting motion between two orientations, and the crystal structure becomes simple cubic (sc) (Tycko et al., 1991). A similar fcc to sc transition is observed in alkali fullerides with 1:1 stoichiometry (Kosaka et al., 1995; Macovez et al., 2008).

Concerning molecular fullerene cocrystals, the prototypical example of a rotator phase is the fullerene-cubane compound. This crystal has been dubbed a "rotor-stator" compound because, at room temperature, the fullerenes exhibit free rotation while the cubane species are static (Pekker et al., 2005). The free-rotator phase is stable down to $140 \mathrm{~K}$, much lower than the transition temperature of pristine $\mathrm{C}_{60}$ and other derivatives (Bortel et al., 2006). Free rotation of the $\mathrm{C}_{60}$ species has been reported or suggested also in other cocrystals, for example, with $\mathrm{CHBr}_{3}$ (Collins et al., 1999) and with p-bromocalix[4] arene propyl ether, where isotropic reorientations persist down to at least $130 \mathrm{~K}$ (Hughes 
et al., 2000). It is interesting to note that the behavior of simple fullerene derivatives such as $\mathrm{C}_{60} \mathrm{O}$ and $\mathrm{C}_{61} \mathrm{H}_{2}$ is opposite to that of most cocrystals: these functionalized fullerenes exhibit an orientational ordering transition at higher temperature than that of pristine $\mathrm{C}_{60}$. The increased critical temperature is ascribed to the fact that the entropy of the disordered (high-temperature) phase of the fullerene derivatives is lower than that of $C_{60}$ because the side adducts must occupy intramolecular voids, so that free rotation is not allowed (Lommen et al., 1994; Meingast et al., 1996).

Solvates with aromatic solvents are usually characterized by stronger intermolecular interactions than other solvates. In the case of the $\mathrm{C}_{60}$ solvate with benzene, at low temperature the fullerenes exist in two distinct orientations (Bürgi et al., 1994), and although a study has suggested the existence of dynamic molecular disorder at room temperature (He et al., 1997), the comparison between solvates with several distinct aromatic solvents indicates that free rotations of the $\mathrm{C}_{60}$ molecules is generally hindered in these systems (Korobov et al., 1999). This leaves open the possibility of a merohedral dynamic disorder, as in pristine $\mathrm{C}_{60}$ below $260 \mathrm{~K}$. The room-temperature crystal structure of the $\mathrm{C}_{60} \cdot 2 \mathrm{C}_{6} \mathrm{H}_{5} \mathrm{Br}$ solvate, for example, was refined assuming two molecular orientations of the fullerenes with occupancy factors of 0.71 and 0.29 (Korobov et al., 1998), which suggests the occurrence of ratcheting motions.

Solvates with halogen-methane or -ethane derivatives generally display orientational disorder of the solvent molecules; this is the case of $\mathrm{CBr}_{2} \mathrm{Cl}_{2}$ or $\mathrm{CBr}_{2}\left(\mathrm{CH}_{3}\right)_{2}$, for example, though not for $\mathrm{CBr}_{2} \mathrm{H}_{2}$ (Ye et al., 2016, 2017). Some cocrystals display simultaneous molecular rotations of both component species, as in the case of the $\mathrm{C}_{60}$ solvate with $\mathrm{Fe}\left(\mathrm{C}_{5} \mathrm{H}_{5}\right)_{2}$ (Espeau et al., 2002; Rozen et al., 2004) and as suggested also for the solvates with some methane derivatives (Collins et al., 2000). An example of molecular dynamics of the intercalant species is shown in Figure 1, which show the results of the characterization of the $1: 1 \mathrm{C}_{60}$ solvate with $(1,1,2)$ trichloroethane. The structure of the solvate, as obtained by refinement of X-ray powder diffraction (XRPD) data, is shown in Figure 1A. Figure 1B exhibits the relaxation times of the trichloroethane species, as measured by dielectric spectroscopy; two distinct relaxation times are observed (Mitsari et al., 2016b) (since this technique is sensitive to changes of the electric dipole moment, it can be used to selectively probe the motion of the polar ethane derivatives).

The presence of two distinct relaxation times has been ascribed to the simultaneous presence in the solvate of two distinct $(1,1,2)$ trichloroethane conformers of different chirality and dipole moment, namely gauche and transoid. The slower dynamics is ascribed to the transoid conformer, whose dipole moment is more than twice that of the gauche conformer, leading to a larger induced polarization of the $\mathrm{C}_{60}$ species [which are highly polarizable due to the large number of $\pi$ electrons (Pederson and Quong, 1992; Macovez et al., 2011)] and thus to a more pronounced electric hindrance against dipolar reorientation.

As mentioned, decomposition of solvates occurs by the loss of the solvent molecules, leaving behind a quasi-pure $\mathrm{C}_{60}$ solid with numerous defects and faults (Michaud et al., 2000). Enthalpies of desolvation are usually given per mole of solvent, and typical values range between 35 and $60 \mathrm{~kJ} / \mathrm{mol}$ (Céolin et al., 2001) although, in few cases, they can be as low as 15 or $20 \mathrm{~kJ} / \mathrm{mol}$ (Jansen and Waidmann, 1995). As a general trend, solvates that are characterized by lower enthalpies of desolvation are characterized by weaker molecular interactions, and thus by lower stability and unhindered fullerene rotation (lower orientational transition temperature). Despite efforts to unveil patterns of common behavior in solvates, however, their variety is such that no simple, universally valid correlations have been found.

Pristine fullerite is a good electron acceptor and usually behaves as an electron-transporting ( $n$-channel) semiconductor. Orientational ordering has an important impact on electron conduction properties. In pristine fullerite, the dc conductivity $\left(\sigma_{\mathrm{dc}}\right)$ decreases by more than one order of magnitude as the temperature is increased through the transition at $260 \mathrm{~K}$ (Katz et al., 2003), and orientational ordering plays an important role also in alkali fullerides (Macovez et al., 2008). The electron affinity and $n$-type conduction are usually preserved by fullerene functionalization, with $\mathrm{C}_{60}$ derivatives exhibiting electron transport properties that are well described by the variable-range hopping model (see also below) (Macovez et al., 2014b; Zachariah et al., 2016; Mitsari et al., 2017) typical of disordered semiconductors.
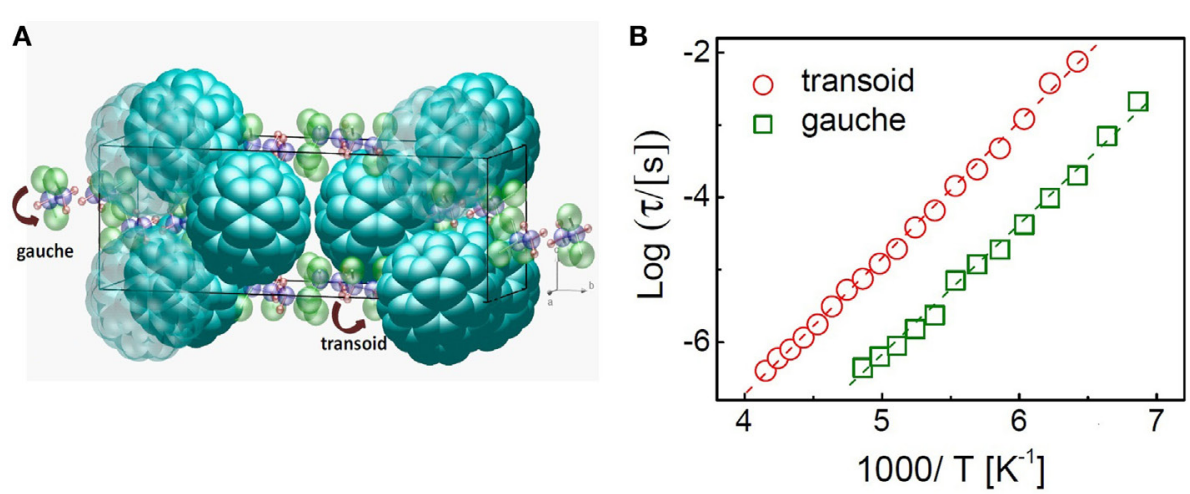

FIGURE 1 | (A) Crystal structure of the 1:1 solvate of $\mathrm{C}_{60}$ with $(1,1,2)$ trichloroethane. The ethane derivatives are present both as gauche and transoid conformers. (B) Relaxation times of the guest molecules in the solvate. Each relaxation is assigned to a different $(1,1,2)$ trichloroethane conformer. Reprinted with permission from Mitsari et al. (2016b). Copyright 2016 American Chemical Society. 
In the case of the brominated $\mathrm{C}_{60} \mathrm{Br}_{6}$ derivative, a deviation from the electronic variable-range hopping behavior has been reported above $215 \mathrm{~K}$, and this conductivity cross-over has been ascribed to a possible onset of orientational dynamics (Zachariah et al., 2016). The electron affinity of fullerene derivatives has spurred a lot of research on fullerene systems aimed at improving the charge transfer and charge transport properties, to achieve, for example, high-efficiency heterojunction solar cells (He et al., 2012; Lai et al., 2014) and air-stable $n$-channel organic transistors (Jones et al., 2007; Usta et al., 2009). When cocrystals are formed with species that do not significantly alter the crystal packing, the isotropic electron conduction properties of pristine fullerite are retained. This is the case of ammoniated fullerenes, where ammoniation can even preserve superconductivity. In more complex systems, electronic conduction can have a lower effective dimensionality (Idé et al., 2014).

$\mathrm{C}_{60}$ and higher fullerenes are hydrophobic: their solubility in water is extremely poor and no stable hydrates can form. Functionalization with polar groups can be employed to improve the hydrophilic affinity and thus the solubility of fullerenes in water. The most studied hydrophilic fullerene derivatives are polyhydroxilated fullerenes (fullerenol, chemical formula $\mathrm{C}_{60}(\mathrm{OH})_{n}$ with $n$ between 6 and 40$)$. The water solubility increases with increasing number of hydroxyl groups, with relatively poor solubility for $n<12$ (Chiang et al., 1994) and good solubility for a higher number of hydroxyl groups (e.g., 16 or 20-24) (Li et al., 1993; Wang et al., 2005). Fullerenols have been suggested to act as proton conductors in water solution and when incorporated inside membranes (Rajagopalan and Oh, 2011; Sardenberg et al., 2011). This is surprising since, as mentioned, in the solid phase of pure derivatives, charge transport occurs via hopping of electronic charge carriers. Recent studies have appeared that address the nature of charge transport in hydrophilic derivatives.

The two related derivatives $\mathrm{C}_{60}(\mathrm{OH})_{24}$ and $\mathrm{C}_{60}(\mathrm{ONa})_{24}$ are particularly interesting in this respect. Both molecules can be synthesized starting from polybrominated fullerene with the maximum possible number of adducts $\left[\mathrm{C}_{60} \mathrm{Br}_{24}\right.$ (Taylor and Walton, 1993)], by substitution and neutralization reactions with sodium hydroxide. Both polyalcohol $(-\mathrm{OH})$ and polyalkoxide $(-\mathrm{ONa})$ derivatives are hydrophilic; the precipitate of the $\mathrm{C}_{60}(\mathrm{ONa})_{24}$ synthesis is a crystalline hydrate with formula $\mathrm{C}_{60}(\mathrm{ONa})_{24} \cdot 16 \mathrm{H}_{2} \mathrm{O}$, while the $\mathrm{C}_{60}(\mathrm{OH})_{24}$ precipitate is a molecular powder with interstitial water clusters that crystallize into ice upon cooling below $273 \mathrm{~K}$ (Macovez et al., 2014a; Zachariah et al., 2015; Mitsari et al., 2017). The XRPD patterns of the pure (waterfree) derivatives exhibit Bragg peaks at basically the same angles, as shown in Figure 2A; instead, very different diffraction patterns are observed in the hydrated materials: while hydrated $\mathrm{C}_{60}(\mathrm{ONa})_{24}$ is crystalline (Zachariah et al., 2015), hydrated $\mathrm{C}_{60}(\mathrm{OH})_{24}$ is much more disordered (see Figure 2A). These facts, together with the observation in the fullerenol case of partial crystallization of interstitial water (Mitsari et al., 2017) indicate that although the interfullerene interactions are basically identical in both derivatives, the heterointeractions with water are qualitatively different. This difference is possibly due to the fact while the polyalcoxy derivative can only act as a H-bond acceptor, the polyalcohol derivative can act both as an acceptor and as a H-bond donor, resulting in a more complex (and partially disordered) structure of the $\mathrm{H}_{2} \mathrm{O}$ molecules in hydrated fullerenol.

The inset to Figure 2B displays the Arrhenius plot of the dc conductivity of the pure (water-free) $\mathrm{C}_{60}(\mathrm{OH})_{24}$ powder (Mitsari et al., 2017), which follows the Shklovskii-Efros variable-range electron hopping model according to which $\log \left(\sigma_{\mathrm{dc}}\right) \sim T^{-1 / 2}$ (where $T$ is the temperature in kelvin) (Efros and Shklovskii, 1975). Similar results have been obtained for pure $\mathrm{C}_{60}(\mathrm{ONa})_{24}$ (Macovez et al., 2014b), which indicates that also hydrophilic fullerene derivatives are electronic conductors in their pure form. Instead, in hydrated $\mathrm{C}_{60}(\mathrm{OH})_{24}$ and $\mathrm{C}_{60}(\mathrm{ONa})_{24}$, the presence of $\mathrm{H}_{2} \mathrm{O}$ molecules results in a dominantly protonic conductivity. This is visible in Figure $\mathbf{2 B}$, where the dc conductivity of the hydrated solid obtained from aqueous solution is observed to be higher than the intrinsic (electronic) conductivity of the pure
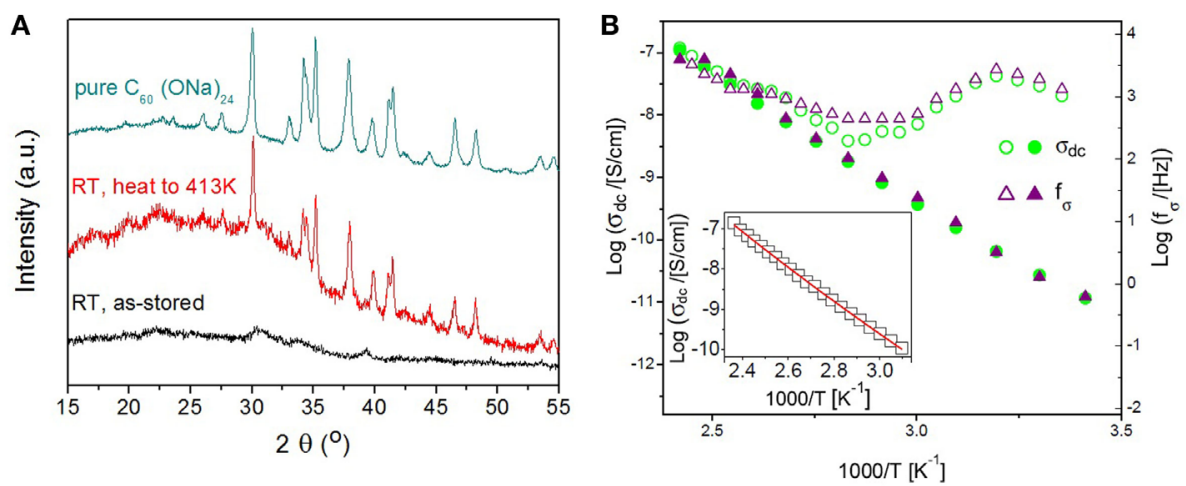

FIGURE 2 | (A) Room-temperature X-ray powder diffraction patterns of hydrated (lower curve) and anhydrous (middle curve) $\mathrm{C}_{60}(\mathrm{OH})_{24}$ fullerenol, in the 20 range between $15^{\circ}$ and $55^{\circ}$. The anhydrous material is obtained from the hydrated one by heating to $413 \mathrm{~K}$. For comparison, the room-temperature pattern of pure $\mathrm{C}_{60}(\mathrm{ONa})_{24}$ (upper curve) is also shown. (B) Arrhenius plot of $\sigma_{\mathrm{dc}}$ (circles) and of the conductivity relaxation frequency $\mathrm{f}_{\sigma}$ (triangles) - see the text for details - measured upon heating an initially hydrated fullerol sample (empty markers) and subsequent cooling of the same, now anhydrous, sample (filled markers). Data between 283 and $413 \mathrm{~K}$ are shown. Inset: Arrhenius plot of $\sigma_{\mathrm{dc}}$ for anhydrous fullerol, and fit with the Shklovskii-Efros variable-range hopping model. Adapted with permission from Mitsari et al. (2017). Copyright 2017 American Chemical Society. 
material by a factor of $10^{3}$. In the figure, $\sigma_{\mathrm{dc}}$ is shown together with the so-called "conductivity relaxation" frequency $f_{\sigma}$, at which the imaginary part of the complex modulus $M=\varepsilon^{-1}$ (inverse of the complex permittivity) is maximum; $f_{\sigma}$ displays the same temperature behavior as $\sigma_{\mathrm{dc}}$, and a similar increase in the hydrated sample.

The water-induced conductivity enhancement occurs not only when water is present as a structural component, as in fullerenol (Mitsari et al., 2017), but also when a pure hygroscopic fullerene derivative such as $\mathrm{C}_{60}(\mathrm{ONa})_{24}$ is stored in a humid atmosphere, as the capture of atmospheric water leads to the formation of a proton-conducting surface layer (Zachariah et al., 2015). Also in the latter case the water-induced conductivity enhancement is quite remarkable: the $\sigma_{\mathrm{dc}}$ value for $\mathrm{C}_{60}(\mathrm{ONa})_{24}$ exposed to humid atmosphere is higher by a factor $10^{4}$ than the anhydrous material (Zachariah et al., 2015). Such conductivity enhancements are in line with those observed in inorganic hygroscopic systems (Cramer et al., 2011; Aragoneses et al., 2013; Haspel et al., 2013) and exploited in resistive humidity sensors (Farahani et al., 2014).

Water-induced conductivity enhancements are generally due to transport of protons or other small ions. Contrary to the case of water chemisorption, which takes place e.g. in hydrated metal oxides (Egashira et al., 1981), the effects reported in hydrated fullerene derivatives do not arise from water splitting, as the extra surface-conductivity contribution vanishes upon heating to moderate temperatures, indicating that the water molecules maintain their integrity. The rationalization of the conductivity enhancements in hydrated fullerene derivatives is that they are due to proton transport by $\mathrm{H}$-bond shuttling, a mechanism by which $\mathrm{O}-\mathrm{H}$ bonds are interchanged between adjacent water molecules, which is responsible for the conductivity of water, ice, and some hydrated organic compounds (Charalampopoulos and Papaioannou, 2011; Knight and Voth, 2012; Wojnarowska et al., 2014). Confirmation of the presence of mobile protons in hydrated polyalcohol and polyalcoxide derivatives is obtained from the analysis of dielectric spectra, where two distinct spacecharge relaxations are observed, associated with the accumulation of, respectively, electronic and protonic charge carriers at fullerene-water interfaces (Mitsari, 2016c; Mitsari et al., 2017).

In the case of the $\mathrm{C}_{60}(\mathrm{ONa})_{24} \cdot 16 \mathrm{H}_{2} \mathrm{O}$ hydrate, $\sigma_{\mathrm{dc}}$ displays a nonmonotonic behavior across the structural dehydration, which takes place around $365 \mathrm{~K}$ (Zachariah et al., 2015). This nonmonotonic behavior is due to the structural change associated with dehydration. A $\sigma_{\mathrm{dc}}$ increase by two orders of magnitude is

\section{REFERENCES}

Allemand, P. M., Khemani, K. C., Koch, A., Wudl, F., Holczer, K., Donovan, S., et al. (1991). Organic molecular soft ferromagnetism in a fullerene $C_{60}$. Science 253, 301-303. doi:10.1126/science.253.5017.301

Aragoneses, A., Tamayo, I., Lebrato, A., Cañadas, J. C., Diego, J. A., Arencón, D., et al. (2013). Effect of humidity in charge formation and transport in LDPE. J. Electrost. 71, 611-617. doi:10.1016/j.elstat.2013.03.003

Assink, R. A., Schirber, J. E., Loy, D. A., Morosin, B., and Carlson, G. A. (1992). Intercalation of molecular species into the interstitial sites of fullerene. J. Mater. Res. 7, 2136-2143. doi:10.1557/JMR.1992.2136

Babu, S. S., Möhwald, H., and Nakanishi, T. (2010). Recent progress in morphology control of supramolecular fullerene assemblies and its applications. Chem. Soc. Rev. 39, 4021-4035. doi:10.1039/c000680g observed some $10^{\circ}$ below the decomposition of the hydrate; this increase appears to be a non-equilibrium contribution, likely due to irreversible changes in the distribution of water around the $\mathrm{C}_{60}(\mathrm{ONa})_{24}$ molecules. Since a similar increase is observed when the pure powder is exposed to humid atmosphere, it is likely that the enhancement is due to a protonic transport mechanism. These studies show that solid $\mathrm{C}_{60}(\mathrm{OH})_{24}$ and $\mathrm{C}_{60}(\mathrm{ONa})_{24}$ only behave as proton conductors in their hydrated forms, and that proton transport takes place through the water network (Zachariah et al., 2015; Mitsari et al., 2017).

Finally, a word is due on the effect of applying pressure on fullerene cocrystals. Just as pure fullerite polymerizes under pressure (Sundqvist, 2004), in the case of cocrystals, application of pressure can result in the formation of non trivial superstructures such as exohedrally intercalated $\mathrm{C}_{60}$ polymers (Cui et al., 2012) or copolymeric structures formed by the reaction of fullerenes with the intercalant (Iwasiewicz-Wabnig et al., 2007). Surprisingly, the application of high pressures leads to the formation of exotic phases with intriguing properties, as discussed in a recent review (Wang, 2015). Compression of $\mathrm{C}_{60}$ cocrystals with $m$-xylene leads to collapse of the molecular constituents; however, though transformed into amorphous carbon clusters, the fullerene moieties maintain their positions and long-range order is preserved (Wang et al., 2012). The resulting material is incompressible and hard enough to indent diamond anvils (Yao et al., 2013). A recent study has shown that similar "super-hard" materials can be obtained from solvates of Buckminsterfullerene (but also of higher fullerenes such as $\mathrm{C}_{70}$ ) with several solvents (Yao et al., 2015). It is worth noticing that pristine $\mathrm{C}_{60}$ does not yield a super-hard material after compression at high pressure (Wang, 2015), hence, cocrystal formation is a prerequisite to obtain super-hard materials from fullerene precursors.

\section{AUTHOR CONTRIBUTIONS}

The author confirms being the sole contributor of this work and approved it for publication.

\section{FUNDING}

The author acknowledges support from the Spanish Ministry of Economy and Competitiveness MINECO through project FIS2014-54734-P and from the Generalitat de Catalunya under project 2014 SGR-581.

Barbour, L. J., Orr, G. W., and Atwood, J. L. (1998). Supramolecular assembly of well-separated, linear columns of closely-spaced C60 molecules facilitated by dipole induction. Chem. Commun. 1998, 1901-1902. doi:10.1039/a804419h

Bortel, G., Faigel, G., Kováts, É, Oszlányi, G., and Pekker, S. (2006). Structural study of C60 and C70 cubane. Phys. Stat. Sol. (b) 243, 2999-3003. doi:10.1002/ pssb.200669165

Bürgi, H. B., Restori, R., Schwarzenbach, D., Balch, A. L., Lee, J. W., Noll, B. C., et al. (1994). Nanocrystalline domains of a monoclinic modification of benzene stabilized in a crystalline matrix of C60. Chem. Mater. 6, 1325. doi:10.1021/ $\mathrm{cm} 00044 \mathrm{a} 033$

Céolin, R., Agafonov, V., Fabre, C., Rassat, A., Dworkin, A., André, D., et al. (1992). Quasicrystal of fullerene C60? J. Phys. I 2, 1.

Céolin, R., Tamarit, J. L., Barrio, M., López, D. O., Toscani, S., Allouchi, H., et al. (2001). Solid-state studies on a cubic 1:1 solvate of $\mathrm{C}_{60}$ grown from 
dichloromethane and leading to another hexagonal $\mathrm{C}_{60}$ polymorph. Chem. Mater. 13, 1349-1355. doi:10.1021/cm001212y

Céolin, R., Tamarit, J. L., López, D. O., Barrio, M., Agafonov, V., Allouchi, H., et al. (1999). A new hexagonal phase of fullerene $C_{60}$. Chem. Phys. Lett. 314, 21-26. doi:10.1016/S0009-2614(99)01091-X

Charalampopoulos, V. G., and Papaioannou, J. C. (2011). Dipole relaxation and proton transport in polycrystalline $\gamma$-cyclodextrin hydrate: a dielectric spectroscopy study. Solid State Ionics. 191, 1-11. doi:10.1016/j.ssi.2011.03.024

Chiang, L. Y., Wang, L.-Y., Swirczewski, J. W., Soled, S., and Cameron, S. J. (1994). Efficient synthesis of polyhydroxylated fullerene derivatives via hydrolysis of polycyclosulfated precursors. J. Org. Chem. 59, 3960-3968. doi:10.1021/ jo00093a030

Collins, C., Duer, M., and Klinowski, J. (2000). Molecular dynamics in crystalline $\mathrm{C}_{60} 2 \mathrm{CHBr}_{3}$. Chem. Phys. Lett. 321, 287-291. doi:10.1016/S0009-2614(00) 00332-8

Collins, C., Foulkes, J., Bond, A. D., and Klinowski, J. (1999). Crystalline $\mathrm{C}_{60}(2 \mathrm{CHBr} 3$ solvate: a solid-state study. Phys. Chem. Chem. Phys. 1, 5323-5326. doi:10.1039/a907129f

Cramer, C., De, S., and Schönhoff, M. (2011). Time-humidity-superposition principle in electrical conductivity spectra of ion-conducting polymers. Phys. Rev. Lett. 107, 028301. doi:10.1103/PhysRevLett.107.028301

Cui, W., Yao, M. G., Liu, D. D., Li, Q. J., Liu, R., Zou, B., et al. (2012). Reversible polymerization in doped fullerides under pressure: the case of $660(\mathrm{Fe}(\mathrm{C} 5 \mathrm{H} 5) 2) 2$. J. Phys. Chem. B 116, 2643-2650. doi:10.1021/jp210712y

de Boer, J. L., van Smaalen, S., Petricek, V., Dusek, M., Marcel, P., Verheijen, A., et al. (1994). Hexagonal close-packed $\mathrm{C}_{60}$. Chem. Phys. Lett. 219, 469-472. doi:10.1016/0009-2614(94)00110-3

Efros, A. L., and Shklovskii, B. I. (1975). Coulomb gap and low temperature conductivity of disordered systems. J. Phys. C Solid State Phys. 8, L49-L51. doi:10.1088/ 0022-3719/8/4/003

Egashira, M., Nakashima, M., Kawasumi, S., and Selyama, T. (1981). Temperature programmed desorption study of water adsorbed on metal oxides. 2. Tin oxide surfaces. J. Phys. Chem. 85, 4125-4130. doi:10.1021/j150626a034

Espeau, P., Barrio, M., López, D. O., Tamarit, J. Ll., Céolin, R., Allouchi, H., et al. (2002). Phase equilibria in the C60 + ferrocene system and solid-state studies of the C60.2ferrocene solvate. Chem. Mater. 14, 321-326. doi:10.1021/ $\mathrm{cm} 0111711$

Farahani, H., Wagiran, R., and Hamidon, M. N. (2014). Humidity sensors principle, mechanism, and fabrication technologies: a comprehensive review. Sensors 14, 7881-7939. doi:10.3390/s140507881

Fernández, G., Pérez, E. M., Sánchez, L., and Martín, N. (2008). Self-organization of electroactive materials: a head-to-tail donor-acceptor supramolecular polymer. Angew. Chem. Int. Ed. 47, 1094-1097. doi:10.1002/anie.200703049

Fleming, R. M., Kortan, A. R., Hessen, B., Siegriest, T., Thiel, F. A., Marsh, P., et al. (1991). Pseudotenfold symmetry in pentane-solvated C60 and C70. Phys. Rev. B 44, 888. doi:10.1103/PhysRevB.44.888

Galtsov, N. N., Prokhvatilov, A. I., Dolgova, G. N., Cassidy, D., Gadd, G. E., Moricca, S., et al. (2007). Intercalation of fullerite C60 with N2 molecules. An investigation by x-ray powder diffraction. Low Temp. Phys. 33, 881-885. doi:10.1063/1.2796156

Hamed, A., Sun, Y. Y., Tao, Y. K., Meng, R. L., and Hor, P. H. (1993). Effects of oxygen and illumination on the in situ conductivity of $\mathrm{C}_{60}$ thin films. Phys. Rev. B 47, 10873. doi:10.1103/PhysRevB.47.10873

Hardie, M. J., and Raston, C. L. (1999). Confinement and recognition of icosahedral main group cage molecules: fullerene C60 and o-, m-, p-dicarbadodecaborane(12). Chem. Commun. 1999, 1153-1163. doi:10.1039/a900787c

Haspel, H., Bugris, V., and Kukovecz, Á (2013). Water sorption induced dielectric changes in titanate nanowires. J. Phys. Chem. C 117, 16686-16697. doi:10.1021/ jp404512q

He, H., Barras, J., Foulkes, J., and Klinowski, J. (1997). Solid-state NMR studies of fullerene C60/benzene solvates. J. Phys. Chem. B 101, 117. doi:10.1021/ jp961708w

He, Z., Zhong, C., Su, S., Xu, M., Wu, H., and Cao, Y. (2012). Enhanced power-conversion efficiency in polymer solar cells using an inverted device structure. Nat. Photonics 6, 591-595. doi:10.1038/nphoton.2012.190

Heiney, P. A., Fischer, J. E., McGhie, A. R., Romanow, W. J., Denenstein, A. M., Mc Cauley, J. P., et al. (1991). Orientational ordering transition in solid $\mathrm{C}_{60}$. Phys. Rev. Lett. 66, 2911-2914. doi:10.1103/PhysRevLett.66.2911
Hughes, E., Jordan, J., and Gullion, T. (2000). Molecular dynamics of C60 in cocrystals of C60 and p-bromocalix[4] arene propyl ether. J. Phys. Chem. B 104, 691-694. doi:10.1021/jp991833i

Idé, J., Fazzi, D., Casalegno, M., Meille, S. V., and Raos, G. (2014). Electron transport in crystalline PCBM-like fullerene derivatives: a comparative computational study. J. Mater. Chem. C 2, 7313. doi:10.1039/C4TC00502C

Iwasiewicz-Wabnig, A., Sundqvist, B., Kováts, É, Jalsovszky, I., and Pekker, S. (2007). Polymerization of the rotor-stator compound C60-cubane under pressure. Phys. Rev. B 75, 024114. doi:10.1103/PhysRevB.75.024114

Jansen, M., and Waidmann, G. (1995). Darstellung und Charakterisierung der Fulleren-Kokristallisate $\mathrm{C}_{60} \cdot 12 \mathrm{C}_{6} \mathrm{H}_{12}, \mathrm{C}_{70} \cdot 12 \mathrm{C}_{6} \mathrm{H}_{12}, \mathrm{CC}_{60} \cdot 12 \mathrm{CCl}_{4}, \mathrm{C}_{60} \cdot 2 \mathrm{CHBr}_{3}$, $\mathrm{C}_{60} \cdot 2 \mathrm{CHCl}_{3}, \mathrm{C}_{60} \cdot 2 \mathrm{H}_{2} \mathrm{CCl}_{2}$. Z. Anorg. Allg. Chem. 14, 621 .

Jones, B. A., Facchetti, A., Wasielewski, M. R., and Marks, T. J. (2007). Tuning orbital energetics in arylene diimide semiconductors. Materials design for ambient stability of N-type charge transport. J. Am. Chem. Soc. 129, 15259-15278. doi:10.1021/ja075242e

Katz,E.A., Faiman, D., Iakoubovskii, K., Isakina, A., Yagotintsev, K. A., Strzhemechny, M. A., et al. (2003). Disorder/order phase transition in C60 thin films studied by surface photovoltage spectroscopy. J. Appl. Phys. 93, 3401. doi:10.1063/ 1.1556187

Katz, E. A., Faiman, D., Mishori, B., Shapira, Y., Shames, A. I., Shtutina, S., et al. (1998). Changes in the photoelectrical properties and generation of photoinduced defects under light/air exposure of $\mathrm{C}_{60}$ thin films. J. Appl. Phys. 84, 3333-3337. doi:10.1063/1.368488

Knight, C., and Voth, G. A. (2012). The curious case of the hydrated proton. Acc. Chem. Res. 45, 101-109. doi:10.1021/ar200140h

Kokubo, K., Matsubayashi, K., Tategaki, H., Takada, H., and Oshima, T. (2008). Facile synthesis of highly water-soluble fullerenes more than half-covered by hydroxyl groups. ACS Nano 2, 327-333. doi:10.1021/nn700151z

Korobov, M. V., Mirakyan, A. L., Avramenko, N. V., Olofsson, G., Smith, A. L., and Ruoff, R. S. (1999). Calorimetric studies of solvates of C60 and C70 with aromatic solvents. J. Phys. Chem. B 103, 1339-1346. doi:10.1021/ jp983165r

Korobov, M. V., Mirakyan, A. L., Avramenko, N. V., Valeev, E. F., Neretin, I. S., Slovokhotov, Y. L., et al. (1998). C60.bromobenzene solvate: crystallographic and thermochemical studies and their relationship to C60 solubility in bromobenzene. J. Phys. Chem. B 102, 3712-3717. doi:10.1021/jp9804401

Kosaka, M., Tanigaki, K., Tanaka, T., Atake, T., Lappas, A., and Prassides, K. (1995). Conducting phase of rapidly cooled AC60 (A=Cs and Rb). Phys. Rev. B 51, 12018. doi:10.1103/PhysRevB.51.12018

Krätschmer, W., Lamb, L. D., Fostiropoulos, K., and Huffman, D. R. (1990). Solid $\mathrm{C}_{60}$ : a new form of carbon. Nature 347, 354. doi:10.1038/347354a0

Lai, Y.-Y., Cheng, Y.-J., and Hsu, C.-S. (2014). Applications of functional fullerene materials in polymer solar cells. Energy Environ. Sci. 7, 1866-1883. doi:10.1039/ c3ee43080d

Li, J., Takeuchi, A., Ozawa, M., Li, X., Saigo, K., and Kitazawa, K. (1993). C60 fullerol formation catalysed by quaternary ammonium hydroxides. J. Chem. Soc. Chem. Commun. 1784-1785. doi:10.1039/C39930001784

Lommen, A. N., Heiney, P. A., Vaughan, G. B. M., Stephens, P. W., Liu, D., $\mathrm{Li}, \mathrm{D}$., et al. (1994). Structure and phase transition of the 6,5-annulene isomer of C61H2. Phys. Rev. B 49, 12572. doi:10.1103/PhysRevB.49.12572

Macovez, R., Goldoni, A., Petaccia, L., Marenne, I., Brühwiler, P. A., and Rudolf, P. (2008). Reversible phase transformation and doubly charged anions at the surface of simple cubic $\mathrm{RbC}_{60}$. Phys. Rev. Lett. 101, 236403. doi:10.1103/ PhysRevLett.101.236403

Macovez, R., Hunt, M. R. C., Goldoni, A., Pedio, M., and Rudolf, P. (2011). Surface hubbard U of alkali fullerides. J. Electron Spectrosc. Relat. Phenom. 183, 94-100. doi:10.1016/j.elspec.2010.07.006

Macovez, R., Mitsari, E., Zachariah, M., Romanini, M., Zygouri, P., Gournis, D., et al. (2014a). Ultraslow dynamics of water in organic molecular solids. J. Phys. Chem. C 118, 4941-4950. doi:10.1021/jp4097138

Macovez, R., Zachariah, M., Romanini, M., Zygouri, P., Gournis, D., and Tamarit, J. Ll. (2014b). Hopping conductivity and polarization effects in a fullerene derivative salt. J. Phys. Chem. C 118, 12170-12175. doi:10.1021/ jp503298e

Martin, N., and Nierengarten, J.-F. (eds) (2012). Supramolecular Chemistry of Fullerenes and Carbon Nanotubes. Weinheim, Berlin: Wiley-VCH Verlag $\mathrm{GmbH} \& \mathrm{Co}$. KGaA. 
Meingast, C., Roth, G., Pintschovius, L., Michel, R. H., Stoermer, C., Kappes, M. M., et al. (1996). Structure, dynamics, and phase transitions in the fullerene derivatives $\mathrm{C} 60 \mathrm{O}$ and C61H2. Phys. Rev. B 54, 124. doi:10.1103/PhysRevB. 54.124

Michaud, F., Barrio, M., López, D. O., Tamarit, J. Ll., Agafonov, V., Toscani, S., et al. (2000). Solid-state studies on a C60 solvate grown from 1,1,2-trichloroethane. Chem. Mater. 12, 3595-3602. doi:10.1021/cm0011099

Michaud, F., Barrio, M., Toscani, S., López, D. O., Tamarit, J. Ll., Agafonov, V., et al. (1998). Solid-state studies on single and decagonal crystals of C60 grown from 1,2-dichloroethane. Phys. Rev. B 57, 10351-10358. doi:10.1103/ PhysRevB.57.10351

Mitsari, E. (2016c). Guest-Molecule Dynamics and Conductivity Effects in CarbonBasede Molecular Solids. PhD thesis, Barcelona: Universitat Politècnica de Catalunya.

Mitsari, E., Romanini, M., Barrio, M., Tamarit, J. Ll., and Macovez, R. (2017). Protonic surface conductivity and proton space-charge relaxation in hydrated fullerol. J. Phys. Chem. C 121, 4873-4881. doi:10.1021/acs.jpcc.6b12530

Mitsari, E., Romanini, M., Zachariah, M., and Macovez, R. (2016a). Solid state physicochemical properties and applications of organic and metallo-organic fullerene derivatives. Curr. Org. Chem. 20, 645-661. doi:10.2174/1385272819 666150730220449

Mitsari, E., Romanini, M., Qureshi, N., Tamarit, J. Ll., Barrio, M., and Macovez, R. (2016b). C60 solvate with (1,1,2)-trichloroethane: dynamic statistical disorder and mixed conformation. J. Phys. Chem. C 120, 12831-12839. doi:10.1021/acs. jpcc.6b02321

Neretin, I. S., and Slovokhotov, Y. L. (2004). Chemical crystallography of fullerenes. Russ. Chem. Rev. 73, 455. doi:10.1070/RC2004v073n05ABEH000891

Pederson, M. R., and Quong, A. A. (1992). Polarizabilities, charge states, and vibrational-modes of isolated fullerene molecules. Phys. Rev. B 46, 13584-13591. doi:10.1103/PhysRevB.46.13584

Pekker, S., Kováts, É, Oszlányi, G., Bényei, G., Klupp, G., Bortel, G., et al. (2005). Rotor-stator molecular crystals of fullerenes with cubane. Nat. Mater. 4, 764. doi:10.1038/nmat1468

Prassides, K., Margadonna, S., Arcon, D., Lappas, A., Shimoda, H., and Iwasa, Y. (1999). Magnetic ordering in the ammoniated fulleride $\left(\mathrm{ND}_{3}\right) \mathrm{K}_{3} \mathrm{C}_{60}$. J. Am. Chem. Soc. 121, 11227-11228. doi:10.1021/ja992931k

Rajagopalan, M., and Oh, I.-K. (2011). Fullerenol-based electroactive artificial muscles utilizing biocompatible polyetherimide. ACS Nano 5, 2248-2256. doi:10.1021/nn103521g

Raston, C. L. (1996). Complexation of fullerenes, in Comprehensive Supramolecular Chemistry, Vol. 1, eds J. L. Atwood, J. E. D. Davies, D. D. Macnicol, and F. Vögtle (Oxford: Pergamon), 777-787.

Rozen, J., Masin, F., Ceolin, R., and Szwarc, H. (2004). Dynamical model for the $\mathrm{C}_{5} \mathrm{H}_{5}$ cycles in the $\mathrm{C}_{60}\left(2 \mathrm{Fe}\left(\mathrm{C}_{5} \mathrm{H}_{5}\right)_{2}\right.$ solvate. Phys. Rev. B 70, 144206. doi:10.1103/ PhysRevB.70.144206

Ruoff, R. S., Tse, D. S., Malhotra, R., and Lorents, D. C. (1993). Solubility of C60 in a variety of solvents. J. Phys. Chem. 97, 3379-3383. doi:10.1021/ j100115a049

Sardenberg, R. B., Teixeira, C. E., Pinheiro, M., and Figueiredo, J. M. A. (2011). Nonlinear conductivity of fullerenol aqueous solutions. ACS Nano 5, 2681-2686. doi:10.1021/nn102913p

Shrestha, L. K., Ji, Q., Mori, T., Miyazawa, K., Yamauchi, Y., Hill, J. P., et al. (2013). Fullerene nanoarchitectonics: from zero to higher dimensions. Chem. Asian J. 8, 1662-1679. doi:10.1002/asia.201300247

Spitsina, N. G., Gritsenko, V. V., Dyachenko, O. A., and Yagubskii, E. B. (2002). Crystal structure of a new fullerene complex: C60-(MT)-2(CS2). Synth. Met. 126, 275-276. doi:10.1016/S0379-6779(01)00569-0

Sundqvist, B. (2003). Interaction between C60 and gases under pressure. Low Temp. Phys. 29, 440-444. doi:10.1063/1.1542508

Sundqvist, B. (2004). Polymeric fullerene phases formed under pressure. Struct. Bond. 109, 85-126. doi:10.1007/b94380
Taylor, R., and Walton, D. R. M. (1993). The chemistry of fullerenes. Nature 363, 685-693. doi:10.1038/363685a0

Tycko, R., Dabbagh, G., Fleming, R. M., Haddon, R. C., Makhija, A. V., and Zahurak, S. M. (1991). Molecular dynamics and the phase transition in solid

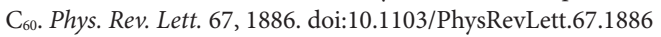

Usta, H., Risko, C., Wang, Z., Huang, H., Deliomeroglu, M. K., Zhukovitskiy, A., et al. (2009). Design, synthesis, and characterization of ladder-type molecules and polymers. Air-stable, solution-processable N-channel and ambipolar semiconductors for thin-film transistors via experiment and theory. J. Am. Chem. Soc. 131, 5586-5608. doi:10.1021/ja809555c

Wang, L. (2015). Solvated fullerenes, a new class of carbon materials suitable for high-pressure studies: a review. J. Phys. Chem. Solids 84, 85-95. doi:10.1016/j. jpcs.2014.06.007

Wang, L., Liu, B., Liu, D., Yao, M., Hou, Y., Yu, S., et al. (2006). Synthesis of thin, rectangular C60 nanorods using m-xylene as a shape controller. Adv. Mater. 18, 1883-1888. doi:10.1002/adma.200502738

Wang, L., Liu, B. B., Li, H., Yang, W. G., Ding, Y., Sinogeikin, S. V., et al. (2012). Long-range ordered carbon clusters: a crystalline material with amorphous building blocks. Science 337, 825. doi:10.1126/science.1220522

Wang, S., He, P., Zhang, J.-M., Jiang, H., and Zhu, S.-Z. (2005). Novel and efficient synthesis of water-soluble [60]fullerenol by solvent-free reaction. Synth. Commun. 35, 1803-1807. doi:10.1081/SCC-200063958

Wojnarowska, Z., Wang, Y., Paluch, K. J., Sokolov, A. P., and Paluch, M. (2014). Observation of highly decoupled conductivity in protic ionic conductors. Phys. Chem. Chem. Phys. 16, 9123-9127. doi:10.1039/c4cp00899e

Yao, M., Cui, W., Du, M., Xiao, J., Yang, X., Liu, S., et al. (2015). Tailoring building blocks and their boundary interaction for the creation of new, potentially superhard, carbon materials. Adv. Mater. 27, 3962-3968. doi:10.1002/ adma.201500188

Yao, M., Cui, W., Xiao, J., Chen, S., Cui, J., Liu, R., et al. (2013). Pressure-induced transformation and superhard phase in fullerenes: the effect of solvent intercalation. Appl. Phys. Lett. 103, 071913. doi:10.1063/1.4818909

Ye, J., Barrio, M., Céolin, R., Qureshi, N., Rietveld, I. B., and Tamarit, J. Ll. (2016). Van-der-Waals based solvates of $\mathrm{C} 60$ with $\mathrm{CBr} 2 \mathrm{Cl} 2$ and $\mathrm{CBr} 2(\mathrm{CH} 3) 2$. Chem. Phys. 477, 39-45. doi:10.1016/j.chemphys.2016.08.012

Ye, J., Barrio, M., Negrier, Ph., Qureshi, N., Rietveld, I. B., Céolin, R., et al. (2017). Orientational order in the stable buckminster fullerene solvate $\mathrm{C} 60 \cdot 2 \mathrm{CBr} 2 \mathrm{H} 2$. Eur. Phys. J. Special Topics 226, 857-867. doi:10.1140/epjst/e2016-60272-x

Zachariah, M., Mitsari, E., Romanini, M., Zygouri, P., Gournis, D., Barrio, M., et al. (2015). Water-triggered conduction mediated by proton exchange in a hygroscopic fulleride and its hydrate. J. Phys. Chem. C 119, 685-694. doi:10.1021/ jp509072u

Zachariah, M., Romanini, M., Zygouri, P., Gournis, D., Tamarit, J. Ll., Barrio, M., et al. (2016). Variable-range electron hopping, conductivity cross-over and space-charge relaxation in C60Br6. Synth. Met. 217, 123-128. doi:10.1016/j. synthmet.2016.03.028

Zhou, O., Fleming, R. M., Murphy, D. W., Rosseinsky, M. J., Ramirez, A. P., Vandover, R. B., et al. (1993). Increased transition temperature in superconducting $\mathrm{Na}_{2} \mathrm{CsC}_{60}$ by intercalation of ammonia. Nature 362, 433-435. doi: $10.1038 / 362433 \mathrm{a} 0$

Conflict of Interest Statement: The author declares that the research was conducted in the absence of any commercial or financial relationships that could be construed as a potential conflict of interest.

Copyright () 2018 Macovez. This is an open-access article distributed under the terms of the Creative Commons Attribution License (CC BY). The use, distribution or reproduction in other forums is permitted, provided the original author(s) or licensor are credited and that the original publication in this journal is cited, in accordance with accepted academic practice. No use, distribution or reproduction is permitted which does not comply with these terms. 